\title{
Dialectologia: \\ Trilhas Seguidas, Caminhos a Perseguir
}

(Dialectology: Traveled Roads and Routes to Travel)

Suzana Alice Marcelino CARDOSO

(Universidade Federal da Bahia)

\begin{abstract}
This text is an attempt to review dialectological studies and to contribute to the reflections on the role of Dialectology in the third millennium. First it focuses authors and works relevant to the development of the methodology applied in that field oflinguistic investigation; then it considers the perspectives and current methodological trends, discussing the different variables which should be taken into account in geolinguistic research at the present moment.
\end{abstract}

KEY-WORDs: Variation; Linguistic Atlases; Geolinguistics; Dialectology.

RESUMO: Neste trabalho procura-se fornecer uma visão dos caminhos percorridos pelos estudos dialetais e trazer uma contribuição à reflexão sobre o papel da Dialectologia no terceiro milênio. Nas primeiras consideraçôes, pôem-se em destaque autores e obras que imprimiram marcas na direção seguida, discutindo a contribuição específica de cada um deles e a forma como se delinearam os passos metodológicos desse ramo dos estudos lingüisticos. Na segunda parte, são feitas consideraçôes sobre os rumos a serem seguidos, examinando-se as tendências metodológicas atuais e discutindo-se a questão referente ao tipo de variáveis que devem interessar e caracterizar os estudos geolingüisticos no momento.

Palavras-Chave: Variação; Atlas lingüisticos; Geolingüistica; Dialectologia. 


\section{Introdução}

Os estudos dialectológicos propriamente ditos iniciam-se num momento da história, século XIX, em que a individualidade geográfica de cada região estava resguardada seja pelo isolamento decorrente da frágil rede de estradas, seja pela dificuldade de comunicação, seja, ainda, pela inexistência de meios tecnológicos que permitissem a interação à distância entre as diferentes áreas, mas resultaram, principalmente, da preocupação com o resgate de dados e a documentação dos diferentes estágios da língua, pois, como chama a atenção o Abbé Rousselot (1887:3, apud Pop: $1950 ; 41)$

Chaque année qui s'écoule emporte avec elle des sons, des constructions, des mots dont la perte est irréparable. Il faut donc se hâter de sauver ce qui a été épargnéjusqu'ici. C'est une oeuvre qui intéresse la science et l'honneur du pays (grifo nosso). Plusieurs l'ont senti, et les ouvrages sur les patois se sont multipliés. On doit rendre hommage à ces patriotiques efforts, ainsi qu'aux pouvoirs publics et aux sociétés savants qui les ont encouragés et soutenus. Mais, il faut bien reconnaître, ce qui a été fait est bien peu en comparaison de ce qui reste à faire (grifo nosso).

As preocupações que manifestava o Abbé Rousselot merecem um breve comentário porque suas palavras ditas no final do século XIX não perderem nem a atualidade nem a pertinência. Preliminarmente, há de considerar-se a ação inexorável do tempo como elemento responsável pelas transformações, pela substituição de estágios da língua, que se perdem, irremediavelmente, no curso da história. Fatos fonético-fonológicos, estruturas sintáticas, recursos morfológicos e variedades léxico-semânticas, fenômenos lingüísticos por natureza mas com implicações com outros ramos do saber constituído em decorrência da interrelação que, com eles, podem apresentar, são resgatados e perenizados por uma ação de cunho dialectológico. $\mathrm{O}$ segundo aspecto a destacar-se diz respeito ao caráter de que se reveste trabalho de tal natureza: é uma questão que interessa a la science et l'honneur du pays. Inscrevem-se, pois, os estudos dialetais, na sua concepção, entre os atos de civismo, e, por que não dizer, constitui-se atribuição-obrigação do próprio exercício da cidadania. Por fim, reconhece que muitos estudos já têm sido realizados e destaca o papel do poder constituído e das sociedades científicas na sustentação de tais projetos, para concluir afirmando que o que já se fez est bien peu en comparaison de ce qui reste à faire. 


\section{Trilhas seguidas}

Ao citar as palavras do Abbé Rousselot, a que acabo de fazer referência, Pop faz um breve comentário que não posso me furtar de transcrever (Pop: 1950; 41):

J'ai reproduit intentionnellemente ces lignes de l'abbé Rousselot, car elles renferment plus d'une vérité et marquent le commencement heureux (grifo nosso) des études dialectales en France.

O "começo feliz" para a Dialectologia, no seu espectro mais amplo, vem a ter dois marcos que imprimem as primeiras, e principais, diretrizes para trabalho de tal natureza: o levantamento de dados da realidade alemã feito por Wenker e a recolha sistemática para o Atlas Linguistique de la France $(A L F)$, obra de Gilliéron e Edmont.

\subsection{Os começos do "caminho"}

Wenker documenta a realidade dos usos que se registram na Alemanha -40.736 localidades com um total de 44.251 respostas coletadas -, recobrindo, assim, ampla extensão do território. Sem controle sistemático de variáveis sociais, verifica-se que faixa etária e sexo não foram pré-determinados nem, a posteriori, podem ser estabelecidos. Da escolaridade dos informantes, porém, e pelo fato de terem sido os questionários encaminhados aos inspetores regionais de escolas que os passavam aos instrutores, tem-se a dimensão: as respostas foram dadas por letrados, responsáveis pelo ensino na região e podem, ainda, contemplar a contribuição de outros aos quais tenham recorrido esses informantes básicos. Essa primeira investida ressente-se não apenas da ausência de controle de variáveis socioculturais dos informantes mas também, e sobretudo, reflete as dificuldades advindas de uma coleta de dados feita por correspondência, o que significa não observados in loco, com profundas implicações para o tratamento de informações fonéticas. Tem, porém, o mérito de dar um passo significativo para o avanço da Dialectologia: a documentação de fatos em distintas regiōes com possibilidade de serem interrelacionados. A intercomparabilidade de dados espacialmente dispostos vai-se constituir, assim, numa das prerrogativas dos estudos dialetais a qual tem superado a linha do tempo e, de certo modo, garantido o continuum desse tipo de investigação. Para isso, apropriadamente, chama a atenção Rossi (1969: 87-8), afirmando que 
(...) a Dialectologia é uma ciência eminentemente contextual, isto é, (...) o fato apurado num ponto geográfico ou numa área geográfica só gan ha luz, força e sentido documentais na medida em que se preste ao confronto com o fato correspondente - ainda que por ausência - em outro ponto ou em outra área (...).

Tal virtude teve a recolha de Wenker - são dados que reúnem a documentação de fatos em diferentes áreas -, nada obstante e até o presente não se ter alcançado uma ampla divulgação de resultados, dos quais os primeiros foram publicados em 1881, em Strassburg, sob o título Sprachatlas des Deutschen Reichs, com um conjunto de seis cartas, duas fonéticas e quatro morfológicas, constituindo o fascículo inicial do Sprachatlas von Nordund Mitteldeutschland, aufGrund von systematisch mit Hülfe der Volksschuler gesammeltem Material aus circa 30.000 Orten.

Se Wenker abre caminho para uma pesquisa diatópica ampla, permitindo a intercomparação de fatos de uma região com outras, o mérito de consolidar definitivamente o método de recolha dos dialetos geográficos vai recair sobre Jules Gilliéron que, em 1887, inicia a coleta de dados para o Atlas Linguistique de la France (ALF) (1902-1910). Sua principal contribuição metodológica reside no fato de basear-se na documentação in loco, no caso específico, recolhida por um único e exímio documentador, Edmond Edmont. As variáveis sociais, embora sejam depreensíveis a partir do exame do perfil dos informantes, não comparecem registradas nas cartas e, também, não foram programaticamente definidas. Assim, observa-se que as idades se estendem dos 15 aos 85 anos; a presença de informantes do sexo feminino é bastante reduzida e, conseqüentemente, assimétrica em relação ao número de informantes do sexo masculino; e, finalmente, o nível de escolaridade vem a ser identificado por dedução das categorias de informantes - os que têm profissão que supõe instrução secundária e aqueles cuja ocupação indica a necessidade apenas de instrução primária. Depois do $A L F$ e dos estudos feitos por Gilliéron sobre os dados nele contidos, uma nova visão do tratamento do fenômeno da variação se estabelece, pois, no dizer de Rossi (1980: 3301, 2a col.)

(...) não apenas a regularidade absoluta das modificações fonéticas recebia o tiro de misericórdia, mas o mesmo acontecia ao mito do dialeto como unidade de desenvolvimento histórico ininterrupto, orgânico e autônomo, preservada ao longo de séculos de interferências de outros dialetos. 
A obra de Giliéron, apesar de recebida com reservas por alguns lingüistas da época, como Maurice Grammont, Édouard Bourciez, Jules Ronjat e Georges Millardet, pôs na ordem do dia a discussão da complexidade do fenômeno lingüístico tanto na perspectiva sincrônica como diacrônica (Rossi:1980) e teve o mérito de marcar o início da aplicação do método da geografia lingüística com rigor científico, cuja consagração advém com o Sprach-und Sachatlas Italiens und der Südschweiz (AIS) de Jaberg e Jud, obra movida pela volonté de fer, como assinala Pop (1950:560) ao reconhecer que

Les difficultés matérielles, les privations, la fatigue et, il faut le dire, la méfiance "des hommes" (pour ne pa dire leur malveillance) n'ont pu fléchir un seul moment la volonté de fer (grifo nosso) de ces deux savants suisses.

O Atlas de Jud e Jaberg se constitui de um volume de introdução, um volume de cartas com oito tomos e mais um volume etnográfico, e teve a sua publicação iniciada em 1928. Contempla informantes diversificados quanto à idade - de 15 a 85 anos -, quanto ao estrato sociocultural camponeses, pessoas com instrução secundária e intelectuais - e quanto ao sexo, sem, porém, a sistemática na observação de tais variáveis em cada ponto, pois, como comenta Pop (1050:576), en ce qui concerne le délicat problème du choix des informateurs, les auteurs de l'AIS onde laissé la plus complète liberté aux enquêteurs. Apresenta, porém, uma grande inovação no que diz respeito ao atlas de Gilliéron exatamente no fato de explorar a relação entre a palavra e a coisa denominada, imprimindo um cunho etnográfico ou antropogeográfico à obra. Se o AIS, por um lado, avança no campo das relaçôes etnolingüísticas, por outro, ainda se ressente da não cumplicidade com a sociologia, questão de que se davam conta os seus próprios autores e sobre a qual refletiam, reconhecendo (apud POP: 1950; 57980) que

Ainsi, par exemple, pour juger le parler d'une commune quelque peu étendue, il aurait fallu interroger des personnes d'âges différents et appartenant à différentes classes sociales. Si nousy avons renoncé, c'est qu'il fallait tenir compte des possibilités pratiques de l'enquête: nous avons eu la chance extraordinaire de trouver trois enquêteurs [ e esses inquiridores foram nada mais nada menos do que Gerhard Rohlfs, Max Leopold Wagner e Paul Scheuermeier !] également qualifiés et également prêts à faire sur les lieux les interrogatoires longs et fatigants dont nous avions besoin; pouvions-nous leur demander de consacrer toute leur vie à cette rude besogne (grifo nosso)? 
Se com Wenker e no atlas da Alemanha se consagra a relevância da intercomparabilidade de dados e com o atlas de Gilliéron se assenta a importância da inquirição in loco, ao passo etnolingüístico dado por Jud e Jaberg no atlas ítalo-suíço se pode acrescentar um outro avanço significativo trazido por Hans Kurath: a escolha de informantes que não apenas representassem os pontos constituintes da rede de localidades definida por região a partir de uma única faixa etária ou de um estrato social também único, mas que trouxessem também um aporte sociocultural e etário.

Sob o título geral de Linguistic Atlas of the United States and Canada, Hans Kurath e seus colaboradores publicam, de 1939 a 1943, o Linguistic Atlas of New England (LANE), com 734 cartas lingüísticas que trazem dados referentes aos estados de Connecticut, Rhode Island, Massachusetts, Vermont, New Hampshire e Maine e da Long Island, aos quais foi acrescentada a província canadense de New Brunswich, que, com as demais, constitui o conjunto de colônias da Nova Inglaterra, fundadas no século XVII.

A grande novidade do atlas de Kurath está no estabelecimento de critérios para escolha dos informantes envolvendo o aspecto geográfico e o social. Assim, os informantes foram selecionados não apenas com vistas a representar a área geográfica sob investigação, mas também de modo a permitir o estabelecimento das relaçóes entre os dados lingüísticos e outros de cunho sociocultural. Desse modo foram três os níveis de escolaridade abordados: a) pessoas com escassa educação formal, pouca leitura e com reduzido contato social; b) pessoas com educação formal mediana, tendo freqüentado a escola média e familiarizadas com maior leitura do que o grupo anterior, além de apresentarem contatos sociais mais extensos; c) e pessoas portadoras de educação de nível superior, geralmente universitária, afeitas a leituras e com amplos contatos sociais. A esses três níveis, somam-se duas faixas etárias: a) idosos, geralmente de mais de 70 anos; e b) meia-idade ou mais jovens.

O controle de variáveis socioculturais na escolha dos informantes estabelecido no Atlas da Nova Inglaterra abre para a geografia lingüística novas perspectivas e faz da obra de Kurath la première tentative de donner, sur une grande échelle, des indications plus précises sur l'aspect social du langage (Pop: 1050; 922).

$\mathrm{Na}$ Península Ibérica, e no que toca mais de perto à língua portuguesa, o Atlas Lingüistico da Península Ibérica (ALPI) imprime uma nova pers- 
pectiva na recolha de dados, aperfeiçoando qualitativamente a investigação que passa a ser realizada por equipes de especialistas na área, à qual se incorpora Portugal a partir de 1953.

Dirigidos por Tomás Navarro, que elaborou o projeto e ficou encarregado da sua execução, os inquéritos lingüísticos para o $A L P I$ foram iniciados em 1931 e realizados até 1936, ocasião em que, por força da guerra civil espanhola, tiveram de ser interrompidos. A partir de então, os materiais coletados passam a contar uma longa história de viagens e mudanças de domicílio. Assim, em 1937, foram levados de Madrid para Valência e logo depois para Barcelona, de onde, em 1938, foram conduzidos a Paris e mais tarde para Nova York, ficando depositados na Columbia University, da qual era professor Dom Tomás Navarro. A retomada dos inquéritos em território espanhol, em 1947, fez com que retornassem de Nova York, em 1950, os materiais coletados na década de 30, e, assim, se completassem os inquéritos. A partir desse segundo momento, incorpora-se Portugal à empreitada de um atlas da Península Ibérica, com a entrada de L.F. Lindley Cintra que realiza, com a participação de Anibal Otero, os inquéritos em Portugal, entre 1953-1954, completando-os em 1956 e perfazendo uma rede de 156 pontos para o domínio galego-português, de um total de 528 que constituía a rede geral do atlas.

Do ALPI publicou-se o volume I, em 1962, com um total de 75 cartas. Recobrindo toda a área da Península Ibérica, fornece dados referentes ao galego-português, ao espanhol e ao catalão e se apresenta como um atlas que extrapola os limites político-geográficos e recobre um grupo de línguas pertencentes a uma mesma família. Em termos metodológicos, procura estabelecer uma relação com alguns dos atlas publicados, como, entre outros, o $A I S, A L C, A L E I C, A L F, A L G, A L R, A L W$, indicando em cada uma de suas cartas a referência aos demais.

\subsection{Trilhas brasileiras}

No que diz respeito ao Brasil, a Geografia Lingüística tem a sua primeira manifestação com um trabalho de cunho regional, o Atlas Prévio dos Falares Baianos (APFB), publicado em 1963, tendo como autor Nelson Rossi e co-autoras Carlota Ferreira e Dinah Maria Isensee. Recobre todo o Estado da Bahia, com uma rede de 50 localidades, que se distribuem pelas diferentes áreas geográficas e culturais. 
O questionário lingüístico usado nas localidades da Bahia é de pouca extensão e tem um total de 179 perguntas (numeradas de 1 a 164, mas com algumas delas desdobradas em $\mathbf{a}, \mathbf{b}$ e c), selecionadas a partir de material recolhido anteriormente em 4 localidades, onde foi aplicado um questionário experimental de cerca de 3600 itens. As perguntas que compuseram o Extrato de Questionário do $A P F B$, agrupadas por área semântica, foram aplicadas mediante a formulação indireta, todavia introduziu-se, na investigação de campo, um comportamento metodológico não usual em trabalhos dessa natureza. Após a aplicação integral do questionário, não ouvidas certas respostas e já familiarizados, como estavam todos os inquiridores, com tais expressões regionais obtidas em outras áreas quando da aplicação do questionário amplo de caráter experimental, perguntou-se diretamente ao informante se ele conhecia a expressão em questão. Fosse qual fosse a resposta, esse dado foi controlado e a resposta dada através do que se convencionou chamar de teste de identificação direta foi cartografada ou não, a depender da caracterização fornecida pelo informante.

O atlas constitui-se de um conjunto de 209 cartas, na sua maioria onomasiológicas mas contando, também, com algumas cartas semasiológicas, assim distribuídas: 198 cartas lingüísticas, 44 das quais são resumos das cartas fonéticas, e 11 cartas introdutórias que fornecem dados complementares de caráter geral. As cartas lingüísticas vêm acompanhadas de notas que contêm ou o discurso dos autores ou o discurso dos informantes, estas últimas, sem dúvida, as mais importantes pois ampliam os dados lingüísticos não apenas no nível do léxico ou da fonética mas também da morfossintaxe, e transmitem melhor o ambiente cultural em que vive o informante.

$\mathrm{O} A P F B$ ao lado dos dados estritamente lingüísticos traz, também, nas suas cartas dados etnográficos, muitos deles acompanhados de ilustrações de objetos segundo a descrição que apresentavam os informantes ou pela exibição que deles faziam.

Seguindo-se ao $A P F B$, surgem quatro atlas lingüísticos que vão dar a conhecer o perfil diatópico do Brasil na direção do Nordeste, atingindo a Paraíba, e no caminho do Sul, alcançando o Paraná. São, assim, publicados o Atlas Lingüistico de Sergipe (ALS), o Esboço de um Atlas Lingüístico de Minas Gerais (EALMG), o Atlas Lingüistico da Paraíba (ALPb) e o Atlas Lingüistico do Paraná (ALPr). 
Embora, por dificuldade de financiamento, publicado somente em 1987, o Atlas Lingüistico de Sergipe quanto à recolha de dados e preparação de cartas se segue imediatamente ao $A P F B$ e tem os seus originais prontos para impressão desde 1973. Foi executado pelo grupo de pesquisadores da Bahia, tendo como autores Carlota Ferreira, Jacyra Mota, Judith Freitas, Nadja Andrade, Suzana Cardoso, Vera Rollemberg e Nelson Rossi. O Esboço de um Atlas Lingüístico de Minas Gerais, de autoria de José Ribeiro, Mário Zágari, José Passini e Antônio Gaio, foi concebido em quatro volumes dos quais se publicou o primeiro em 1977, estando os demais no prelo. Elaborado por Maria do Socorro Silva e Aragão e Cleusa Bezerra de Menezes, o Atlas Lingüistico da Paraíba está estruturado em três volumes dos quais os dois primeiros foram editados em 1984. Como último dessa série aparece o Atlas Lingüistico do Paraná (ALPr), de autoria de Vanderci de Andrade Aguilera, inicialmente tese de doutorado defendida em 1990, publicado em 1994, em dois volumes.

Esses atlas apresentam em comum a fidelidade aos princípios da geografia lingüística. No que diz respeito à metodologia seguida, porém, diferenciam-se no que se refere ao controle de variáveis sociolingüísticas. Dessa forma, o $A L S$ e o $A L P r$ permitem a identificação, em cada ponto da rede, dos informantes, diferenciando-os, com sinalização cartografada, conforme o gênero. Assim identificados e consultando-se as notas específicas sobre cada informante, outros dados sociolingüísticos, tais como idade, profissão, natureza da escolaridade, podem ser resgatados e tornam-se passíveis de tratamento sistemático. $\mathrm{O} A P F B$ procede, nas cartas, a uma indicação dos informantes, vinculada à qualidade técnica do registo, a qual permite, com a consulta às notas introdutórias, identificar cada um deles e, conseqüentemente, estabelecer as suas características sociolingüísticas. Esses três atlas têm em comum um outro traço metodológico: a apresentação, em carta, de notas que refletem comentários dos informantes e/ou dos inquiridores, nas quais se encontram não só dados lingüísticos mas também sociolingüísticos e etnográficos.

Ao lado desses atlas publicados, encontram-se em andamento outros de cunho regional - atlas lingüístico etnográfico da região Sul, atlas lingüístico etnográfico dos pescadores do Rio de Janeiro, atlas lingüístico de São Paulo, atlas lingüístico do Ceará, atlas lingüístico de Mato Grosso do Sul - e em diferentes estágios de elaboração. 
A esse conjunto de atlas regionais vem juntar-se, presentemente, o Projeto Atlas Lingüístico do Brasil - Projeto ALiB, iniciado em 1996, por ocasião do Seminário Caminhos e Perspectivas para a Geolingüística no Brasile dirigido por um Comitê Nacional constituído por Jacyra Andrade Mota, Maria do Socorro Silva e Aragão, Mário Roberto Lobuglio Zágari, Vanderci de Andrade Aguilera, Waler Koch e Suzana Alice Marcelino Cardoso, que o preside. Esse projeto retoma a idéia de um atlas lingüístico geral do Brasil, lançada em 1952 e não implementada até então.

Com objetivos bem definidos, o Projeto ALiB se propõe descrever a realidade lingüística do Brasil, no que tange à língua portuguesa, com enfoque prioritário na identificação das diferenças diatópicas e estabelecer isoglossas com vistas a traçar a divisão dialetal do Brasil, tornando evidentes as diferenças regionais através de resultados cartografados em mapas lingüísticos e de estudos interpretativos de fenômenos considerados.

Do ponto de vista metodológico, o Projeto $\mathrm{ALiB}$ atende aos princípios da Geografia Lingüística e introduz controles de natureza sociolingüística. Assim, ao definir o perfil dos informantes, foi considerada, sistematicamente, a participação de homens e mulheres de duas faixas etárias - de 18 a 30 e de 45 a 60 anos - e introduzido, para as capitais de Estado, o controle da diferenciação sociocultural com dois grupos distintos de informantes - com escolaridade até a $4^{\mathrm{a}}$ série e com nível universitário. O projeto ao tempo em que prioriza a informação diatópica, prevê o controle de variáveis sociais, procurando, assim, alcançar uma visão multidimensional da língua portuguesa no Brasil.

\subsection{Mais uma trilha}

No que diz respeito à América Latina, em geral, merece destacar-se o Atlas Lingüístico Diatópico e Diastrático do Uruguai (ADDU), que se desenvolve sob a responsabilidade de Adolfo Elizaincín, da Faculdad de Humanidades de la Universidad de la República (Uruguai), e Harald Thun, do Romanisches Seminar da Christian-Albrechts-Universität zu Kiel (Alemanha), com publicação dos primeiros volumes prevista para 2000. Partindo da verdade inconteste de que (Thun; Forte; Elizaincín:1989, 28) la variación lingüistica se manifesta, por lo menos, en tres dimensiones (...) diatópica, diastrática e diafásica, declaram os autores estarem persuadidos de que el 
Atlas lingüistico tiene la obligación y es además capaz de dar una mensagen de la multidimensionalidady de las interrelaciones de los fenómenos variacionales. Reconhecem, no entanto, a amplitude da dimensão diafásica e por dela terem levado em consideração apenas una porción infima (id., p.42), optaram por não incluir no título do projeto o termo "diafásico". Nada obstante, a apuração desse nível da variação se fundamenta em várias perguntas incluídas na parte 3 do Cuestionario, nas anotaçôes de mudança de registro lingüístico, nas observaçóes às respostas das perguntas do questionário, consideradas na relação entre perguntas preliminares (dados sobre localidade, etc.) e as perguntas propriamente ditas do questionário, além do que revelam as entrevistas dirigidas.

\subsection{As linhas gerais do "caminho"}

Esse breve "caminho" apresentado, em que ponho em destaque momentos, nomes e atlas pinçados no curso da história dos estudos dialetais, tem uma intenção definida: mostrar, de forma ilustrativa, os degraus percorridos pela Dialectologia e os avanços graduais que o método geolingüístico vem alcançando.

Assim, e como se pode observar, à preocupação com a identificação das diferenças espaciais, ponto de partida das pesquisas dialetais, somamse, num processo de apuração e depuração do método, a priorização da recolha in loco dos dados, a busca dos elementos etnográficos complementares aos dados lingüísticos e, finalmente, a inserção de variáveis sociais nos critérios de escolha dos informantes, capazes de tornar mais explícitas as relaçōes língua e sociedade, fatos lingüísticos e fatos sociais, e trazer a juízo causas dantes não conhecidas.

\section{Caminhos a perseguir}

A essa altura, há de perguntar-se: a Dialectologia permanece diatópica ou deve direcionar-se para aspectos etno-diatópico-sociais? Eis a questão para cujo entendimento necessário se faz uma vista d'olhos sobre as dimensões que têm tomado os estudos de Geografia Lingüística, na atualidade, os objetivos que buscam atingir e a metodologia de que se têm valido. 
Do ponto de vista dos espaços que recobrem, os atlas lingüísticos considerados a partir de Gilliéron, procuram responder a diferentes objetivos. Assim, e como reconhece Alinei (1994:21) si ottengono quattro tipi di atlanti, dalpiù piccolo al più grande: (i) regionali, (ii) nazionali, (iii) di gruppo linguistico, (iv) continentali, classificação a que acrescenta o comentário de que, na atualidade, não existem, ainda, atlanti di una intera famiglia linguistica nem tanto meno, un atlante linguistico mondiale.

Segundo a dimensão político-geográfica recoberta pelos atlas já publicados, ainda que se estabeleça uma gradação do aspecto regional ao continental, o empreendimento geolingüístico começou, efetivamente, com atlas nacionais - o Atlas Linguistique de la France - e só depois, sentindo-se a necessidade de aprofundar o conhecimento de cada área, chega-se aos atlas regionais, hoje numerosos não apenas no continente europeu como no americano.

$\mathrm{O}$ fato de os atlas nacionais circunscreverem-se a fronteiras políticas, estabelecendo um termo no espaço geográfico para a descrição lingüística, quando se sabe que os limites lingüísticos ultrapassam, quase sempre, os limites políticos, conduz ao aparecimento de atlas que perseguem os caminhos das línguas e dos dialetos, como diz Alinei (1994: 22), al di là delle frontiere politiche, vindo a estabelecer, assim, fronteiras lingüísticas, como sucede com o Atlas Linguistique Roman (ALiR), cujo volume I circula desde 1996. Apesar da amplitude de que se revestem, os atlas de famílias de língua, como sucede com o $A L i R$, têm, também, condicionamentos, uma vez que deixam de fora tutte le correnti di prestiti, sia immigratorie che emigratorie, che vanno al di là non solo dei confini politici ma anche di quelli linguistici (Alinei: 1994; 22). Essa preocupação, por certo, conduziu o próprio Alinei à pergunta Quali dovebbrero essere allora le frontiere negli atlanti de scala più grande (...)? (Alinei: 1994; 22), para a qual, ele próprio dá a resposta:

Certamente nè politiche nè linguistiche: perchè non esistono frontiere politiche che coincidano com famiglie linguistiche, e le frontiere delle famiglie linguistiche comprenderebbero più continenti.

A resposta concreta, porém, a essa questão vem a ser dada pelos atlas transnacionais, como o Atlas Linguarum Europae (ALE).

Se a amplitude da investigação permite, segundo a área territorial recoberta, a classificação dos atlas em regionais, nacionais, de famílias de línguas e continentais - o que nos dá, hoje, na perspectiva geográfica, um 
panorama diversificado -, do ponto de vista da tipologia metodológica, ou, mais especificamente, da finalização na apresentação dos dados, três categorias de atlas podem, na atualidade, ser identificadas: atlas com apresentação cartográfica dos dados, ilustrados, por exemplo, com o $A L F$, o $A L P I$ e o $A P F B$, entre outros; atlas interpretativos, como o $A L i R$ e o $A L E$ que aos dados cartografados agregam estudos específicos e de análise; e os atlas parlants, que permitem um contato direto do leitor-ouvinte com a realidade oral da área representada. A preocupação, porém, com a interpretação dos materiais cartografados tem acompanhado a publicação de atlas nacionais sob a forma de monografias e estudos específicos, sobretudo nos anos trinta, como assinala Alinei (1994:23).

A essas considerações gerais de caráter metodológico, que assinalam os caminhos que vêm sendo seguidos, necessário se faz acrescentar uma breve reflexão sobre a conjuntura sociopolítica do momento, antes de buscar responder, diretamente, à questão inicialmente formulada.

Uma rápida visão da realidade atual das comunidades lingüísticas mostra as grandes transformações pelas quais têm passado as relações entre os povos. Do isolamento semitotal, caminha-se para a quebra de limites e fronteiras, movida pelo avanço dos meios de comunicação, pela interligação constante entre os centros de povoamento, pelo deslocamento mais intenso dos habitantes de uma região para outra, pela redefinição da constituição demográfica, pela flutuação da população de cada área, estimulada pelos novos mecanismos de caráter econômico e social. Isso tudo leva a que se tenha, hoje, por um lado, usuários da língua mais sedimentados em suas regiões e, por outro, falantes que não só têm grande mobilidade mas também convivem com uma massa também móvel. De outra parte, sobretudo nos países em desenvolvimento, verifica-se a emergência de falantes pertencentes a classes marcadas por um menor grau de escolaridade, que ascendem socialmente em decorrência dos benefícios da escola e do processo de profissionalização. Acresce a isso, a grande mobilidade das massas rurais para os grandes centros urbanos que se verifica, principalmente, nos países mais jovens, do que decorre uma maior interação campo-cidade com reflexos sociais, econômicos e lingüísticos.

Se tomarmos para ilustração um país jovem, o Brasil, podemos fazer algumas constatações no curso de meio século. Assim, a população do Brasil, segundo o censo de 1950, atingia a cifra de 51944397 habitantes, dos 
quais 33161506 se situavam nas zonas rurais e apenas 18782891 estavam estabelecidos nas zonas urbanas, ou seja, aproximadamente $63 \%$ da população se encontrava no campo e apenas $37 \%$ nas grandes cidades. Os meios de comunicação - rádio, televisão, telefone - tinham um perfil muito tímido cujos dados não vêm registrados nas estatísticas para esse ano. A extensão da rede de estradas de ferro em tráfego alcançava $36681 \mathrm{~km}$. As rodovias se estendiam por $341035 \mathrm{~km}$. As empresas aéreas civis atingiam um percurso de 96600775 km e a navegação marítima e a navegação fluvial apresentavam um movimento de 406 embarcações em tráfego. Decorridos quase cinqüenta anos, a situação que apresenta, hoje, o país no tocante a esses mesmos itens, é - como não poderia deixar de sê-lo - bem diferente. Conta-se com os seguintes números, segundo os dados do censo de 1991, de referência aos itens citados: população geral de 146917459 habitantes dos quais 110875826 se situam na zona urbana e 36041633 na área rural, o que revela uma total inversão dos números se comparados aos registrados para 1950; a rede telefônica, que nem chega a ser levantada nas estatísticas disponíveis de 1950, apresenta, para 1991, um total de 15922 localidades atendidas com 14426673 telefones instalados; a rede ferroviária conta com $30282 \mathrm{~km}$ - caso único de modificação para menos com uma redução de cerca de 6000 km em relação a 1950, fato deplorável, para não dizer criminoso, em relação ao sistema de transporte do país; o tráfego aéreo atinge $287761775 \mathrm{~km}$; e a navegação conta com um movimento total de 46310 embarcações.

Essa ilustração da realidade atual, feita com dados do Brasil, embora apresente muito de comum a outras áreas, não se repetirá de maneira idêntica em todas as partes, mas pode contribuir para uma reflexão sobre o perfil dos informantes e a natureza dos dados que interessem mais de perto à Dialectologia registrar.

Diante do quadro atual, qual deve ser o caminho da Dialectologia em relação a variáveis a considerar:

i) Ater-se unicamente à variável diatópica?

ii) Introduzir outras variáveis na apresentação de dados, colocandoas pari passu à variável diatópica?

iii) Priorizar a variável diatópica mas contemplar as informações com dados de outras variáveis e, nesse caso, quais e de que modo? 
São perguntas que se póem e para as quais tentamos encontrar respostas.

Estou convencida, como muitos também estão, de que a prioridade de dados a serem contemplados em um atlas lingüístico deve ser dada à informação diatópica, se não for por outras razões, pelo menos o será pela própria natureza do trabalho. Em outras palavras, a essência da informação de um atlas reside no dado de natureza espacial, como enfaticamente afirmam Contini e Tuaillon (1996:7):

La dialectologie a pour tâche essentielle d'étudier la variation géolinguistique. Mais avant d'aborder la variation, il doit relever les données linguistiques d'une micro-société de base, une commune, qui sur l'atlas linguistique devient un point.

O dado de natureza espacial deveria, e creio que deverá ainda, espelhar as particularidades de cada rincão, o que nele de mais peculiar e próprio se registra. Por essa razão, a recolha de informaçóes sempre teve pressupostos muito claros de modo a permitir atingir-se o fim colimado. As condiçóes do mundo atual, no entanto, nos levam a refletir sobre algumas questôes.

Pickford (1956), já em meados do novecentos e quando ainda não se tinham generalizado os princípios da Sociolingüística contemporânea, ao fazer críticas ao método seguido para o Atlas Lingüístico dos Estados Unidos e do Canadá e pela Dialectolgia em geral, põe em destaque questôes que, se não são inteiramente pertinentes, são pelo menos justificáveis do ponto de vista de uma visão sociológica dos fatos e dos processos.

Logo de início, levanta "suspeita" sobre a "mecânica imitação" (1956:211) dos procedimentos adotados pela Dialectologia na Europa, a qual me parece infundada. Na verdade, o método finda por ser o mesmo, de um de outro lado do oceano, mas a sua aplicação reflete, necessariamente, a adaptação ao ambiente em que é posto em prática. Se na Europa, como a própria socióloga o diz, os estudos dialetais ajudaram a resolver questões de geografia humana, nos países de surgimento mais recente, como o Brasil, esse mesmo serviço também é prestado pela Dialectologia. A história dos povos será sempre a mesma, no sentido de fatos que se sucedem no curso do tempo; o corte, ou recorte, que os estudos dialetais permitem fazer para dar a sua contribuição ao entendimento desses mesmos fatos é que vai diferenciar-se entre um país jovem e países de história milenar. 
Refere-se, também, a Autora a "erros de confiabilidade" (1956: 214217) dos dados geolingüísticos, apontando como exemplo a generalização de características $\mathrm{da}(\mathrm{s})$ pessoa(s) entrevistada(s) às pessoas não entrevistadas, ou seja, à área considerada. Mais uma vez há de reconhecer-se que o bom seria, numa região em estudo, poder-se ouvir e documentar a totalidade dos moradores da área - de diferentes sexos, idades, profissóes, escolaridade, etc. - , mas isso não é possível nem para a ciência da linguagem nem para os demais ramos do conhecimento científico. O viés de desconfiança que a Autora quer atribuir aos dados geolingüísticos não procede, pois ao afirmar-se a presença de tais ou quais características numa dada área, não se está negando a existência de outros nem dizendo da exclusividade dos trazidos à consideração.

Detém-se, ainda, Pickford (1956: 217-220) no exame dos erros da investigação direta, mostrando que certos indicadores sociais da linguagem podem passar despercebidos em virtude da posição de correção e vigilância da fala assumida pelo informante. Nesse ponto tem razão a Autora pois até então não era comum na documentação de dados dialetais introduzir-se o discurso livre ou o relato de fatos e acontecimentos. Apesar, porém, de assim também o reconhecer, não posso deixar de chamar a atenção para o fato de que os processos técnicos, que permitem o registro magnetofônico de falas na sua inteireza, constituem-se em avanços recentes e, conseqüentemente, em acontecimento não simultâneo com o início das investigações sistemáticas de cunho dialetal.

Considerando-se questóes, como as tomadas como referência, que vêm sendo levantadas ou podem vir a ser levantadas, algumas perguntas se põem, hoje, para o dialetólogo e requerem algumas considerações.

Primeiramente, deve-se ainda restringir-se o conjunto de informantes de uma área a homens e mulheres analfabetos? É uma questão que se põe, hoje, com muita evidência, para os estudos dialetais.

Em segundo lugar, a complexidade da vida social tem acentuado peculiaridades lingüísticas entre grupos etários, particularizando, assim, o uso dos mais jovens em relação ao dos mais avançados em idade, fato cuja constatação já perpassa os caminhos da Dialectologia desde os seus primórdios como se vê da própria preocupação do Abbé Rousselot, trazida à lembrança por Pop (1952: 43): 
La connaissance de l'âge des sujets observés est indispensable afin de pouvoir comparer les divergences existant entre le parler des jeunes et celui des vieillards, et déterminer leur point de départ.

Um terceiro aspecto tem a ver com a estratificação social, mais evidente nos centros urbanos, onde os usos linguageiros podem refletir preferências de grupos e denotar categorias sociais decorrentes do grau de escolaridade dos falantes e também da sua própria integração social.

Essa nova configuração da sociedade e os apelos diversos do mundo atual, por certo, estão na base da afirmação de Chambers e Trudgill (1994:45) que, ao tratarem de uma breve história da geografia lingüística, afirmam que el futuro de la geografía lingüistica depende de la capacidad de sus seguidores para abarcar e incorporar los intereses y quizás la metodología de la dialectología urbana.

Nesse campo, a contribuição laboviana tem sido relevante. A compreensão dos fenômenos sociais e de suas implicações nos fatos de língua mostrados por Labov (1966; 1971; 1972a; 1972b; 1975) tem conduzido a que os estudos dialetais, pelo menos nos países de história mais recente, contemplem a sua metodologia com aspectos que permitam levar em consideração preocupações de tal natureza.

E retomo a questão inicialmente posta: a Geolingüística deve continuar a priorizar o aspecto diatópico? Ou deve fundamentar-se em outros processos variacionais, como o grau de escolaridade, o sexo e a idade? $\mathrm{Ou}$, ainda, pode a elaboração de um atlas lingüístico, hoje, desconhecer as circunstâncias socio-político-culturais do momento e prescindir da sua análise para a coleta e apresentação de dados?

Ao tentar responder a essas questóes e justificar a minha posição, façoo pensando em países de pouca idade, como o Brasil, não tendo, porém, certeza, de poder generalizar esses pontos de vista para áreas de história lingüística sedimentada em muitos séculos.

Não creio que se deva, e mesmo se possa, aplicar, por inteiro, à Geolingüística a metodologia da Dialectologia vertical, ou Sociolingüística, pois diversos são os campos de atuação e bem especificados como os distingue Stehl (1996: 621) ao reconhecer quatro tipos de Dialectologia: a geolingüística, a sociolingüística, a pragmatolingüística e a diacrônica. Os 
dados geolingüísticos, ademais, não devem ser argüidos de pobreza sociológica porque a complexidade de fatores sociais a considerar na análise dos fenômenos lingüísticos não pode ser contemplada, indistintamente, em todo e qualquer tipo de abordagem nos estudos da linguagem.

O caráter extensivo da Dialectologia parece continuar evidente pois trará sempre um retrato das áreas consideradas, fazendo um diagnóstico da realidade da língua, mapeando-a na superfície, mas permitindo:

(i) A investigação de cunho histórico com o estabelecimento como que de camadas que contribuirão grandemente para a construção da socio-história da língua considerada e a cuja evidência, e pensando no português do Brasil, se refere Houaiss (1985:127):

(...) o mapeamento confiável da dialectologia brasileira a exemplo do que sonhou Antenor Nascentes e realizou parcialmente Nelson Rossi com seus colaboradores - mapeamento do qual, pelas igualdades unitárias e globalizantes, será possivel "recapitular" o processo passado que terá gerado o presente descrito por essa dialectologia.

(ii) A definição de áreas lingüísticas, com a indicação de diferenças e identidades.

(iii) $\mathrm{O}$ estabelecimento, pelo confronto, de variáveis sociais conjugadas à distribuição espacial.

Creio que a geolingüística hoje, neste final de milênio, começo de um novo, deve continuar a priorizar a variação diatópica, abrindo, porém, espaço para o controle de outras variáveis como sexo, idade e escolaridade, sem a busca obcecante da quantificação, mas tomando-as, de forma exemplificativa e não exaustiva, de modo a complementar os próprios dados areais pois, não se propondo dizer o absoluto - essa é uma região exclusiva de tal ou qual fenômeno -, retrata as particularidades sem assegurar o caráter de exclusividade. Tomar diferentes tipos de falantes, diversificados socialmente, significa, por outro lado, ampliar o espectro da fotografia, mas não quererá dizer que se possa, ipso facto, qualificar a natureza dessa fotografia, afirmando o caráter de exclusividade ou dominância do fenômeno considerado.

A Geolingüística, como a própria denominação lhe impõe e a natureza dos dados que busca reunir exige, permanece, na sua essência, diatópica sem, porém, descurar do aspecto multidimensional de que se reveste $\mathrm{o}$ ato de fala e de cuja consideração, no mundo atual, não se pode eximir. 


\section{REFERÊNCIAS BibLIOGRÁFicas}

Aguilera, V. de A. (1994) Atlas Lingüistico do Paraná (ALPr). Curitiba: Imprensa Oficial do Estado.

Alinei, M. (1994) L'Atlas Linguarum Europae: resultati, struttura, storia, prospettivi. In: P. G. Mouton (org.) Geolingüistica. Trabajos Europeos. Madrid: Conjero de Investigaciones Científicas.

Anuário Estatístico do Brasil - 1954. Ano XV, Rio de Janeiro: IBGE-Conselho Nacional de Estatística, 1954.

Anuário Estatístico do Brasil -1993. Rio de Janeiro: Fundação Instituto Brasileiro de Geografia e Estatística-IBGE, 1993.

Aragāo, M. do S. \& Menezes, C. B. de (1984) Atlas Lingüístico da Paraíba $(A L P b)$. Brasília: UFPB/CNPq, Coordenação Editorial.

Atlas Lingüístico de la Peninsula Ibérica (ALPI).(1962) Madrid: CSIC. Atlas Linguistique de la Wallonie (ALW) (1953-1987) Liège: Imprimerie H.Vaillant Carmanne S.A.

Atlas Linguistique Roman (ALiR) (1996) Roma: Instituto Poligrafico e Zecca dello Stato.

Bottiglioni, G. (1933-1942) Atlante Linguistico Etnografico Italiano della Corsica, I-IX. Pisa.

Chambers, J.K. \& Trudgill, P. (1994) La Dialectología. Madrid: Visor Libros. Contini, M. \& Tuaillon, G. (1996) Introduction. In: Atlas Linguistique Roman. Vol.I. Présentation. Roma: Instituto Poligrafico e Zecca dello Stato. Contini, M. (1994) Un projet européen de géolinguistique: l'Atlas Linguistique Roman. In: P. G. Mouton (org.) Geolingüistica. Trabajos

Europeos. Madrid: Conjero de Investigaciones Científicas.

Ferreira, C., Freitas, J., Mota, J, Andrade, N. Cardoso, S. Rollemberg, V. \& Rossi, N. (1987) Atlas Lingüistico de Sergipe (ALS). Salvador: Universidade Federal da Bahia / Fundação Estadual de Cultura de Sergipe. Gilliéron, J. \& Edmont, E. (1902-1910) Atlas Linguistique de la France $(A L F), 35$ fasc. Paris: Honoré Champion.

GrIeRA, A. I-V(1923-1939); VI-X (1962-1964). Atlas Lingüistic de Catalunya $(A L C)$. Barcelona: Institut d'Estudis Catalans-La Polígrafa.

HouAISs. A. (1985) O Português no Brasil. Rio de Janeiro: UNIBRADE.

JABERG, K. \& Jud, J. (1928-1940) Spraach-und Sachatlas Italiens und der

Südschweiz, I-VIII. Zofingen: Rieger \& Co.

KuRATH, H. et alii. (1939-1943) Linguistic Atlas of New England (LANE).

Brown University Press. 
Labov, W. (1966) The Social Stratification of English in New York City. Washington: Center for Applied Linguistics.

(1971) Some principles of linguistic methodology. Language in Society,

1: $97-120$.

(1972) Linguage in the Inner City. University of Pennsylvania Press.

(1975) Empirical foundations of linguistic theory. In: AusterLITZ,

R. (ed.) The Scope of American Linguistics. Lisse: Peter De Ridder Press.

- (1983) Modelos Sociolingüisticos. Trad. de Don Ramón de la Cruz.

Madrid: Ediciones Cátedra.

Mouton, P. G. (org.) (1994) Geolingüistica. Trabajos Europeos. Madrid:

Conjero de Investigaciones Científicas.

Nascentes, A. (1953) O Linguajar Carioca. Rio de Janeiro: Simões.

PICKFORD, R G. (1956) American linguistic geography: a sociological appraisal. Word: 12: 211-233.

Pop, S. (1950) La Dialectologie. Aperçu Historique et Méthodes d'Enquêtes Linguistiques. Louvain: Chez l'Auteur.

Pop, S. \& Petrovici, E. (1938-1942) Atlasul Lingvistic Român (ALR), I-III.

Cluj-Sibiu-Leipzig: Muzeul Limbii Române din Cluj.

Ribeiro, J., Zágari, M., Passini, J. \& Gaia, A. P. (1977) Esboço de um Atlas

Lingüistico de Minas Gerais (EALMG). Rio de Janeiro: Ministério da Educação e Cultura - Casa de Rui Barbosa - Universidade Federal de Juiz de Fora.

Rossi, N. (1963) Atlas Prévio dos Falares Baianos (APFB). Rio de Janeiro:

MEC-Instituto Nacional do Livro.

(1980) Đialectologia. In: HouAISs. A. (ed.) Enciclopédia Mirador Internacional. V.7. São Paulo: Melhoramentos: 3298-3304.

(1967) Dialectologia. Alfa, 11: 89-115.

(1969) Os falares regionais do Brasil. In: Atas. O Simpósio de São Paulo. São Paulo.

SÉGUY, J. et alii. (1954-1973) Atlas Linguistique dela Gascogne, I-VI. (ALG).

Paris: CNRS.

STEHL, T. (1996) Competenza, pragmatica e linguistica della variazione: problemi d'inchiesta e d'interpretazione in geolinguistica. In: E. RADTKE $\&$ H. Thun (orgs.) Neue Wege der Romanischen Geolinguistik: Akten des Symposiums zur Empirischen Dialektologie. Kiel: Westensee-Verl.

Thun, H., Forte, C. E. \& Elizaincín, A. (1989) El Atlas lingüístico Diatópico y Diastrático del Uruguay (ADDU). Presentación de un proyecto. Iberoromania, 30: 26-61. 